\title{
exercício da escrita e da escuta como instrumentos de aprimoramento da prática clínica
}

\author{
The exercise of writing and listening as instruments \\ for improving clinical practice
}

\section{Daniele Santos Andrade ${ }^{1}$ (1) Liz Torres Pedreira ${ }^{2}$ (1) Vitoria da Silva Costa Machado Milheiro 3 (1) Yasmin Vidal Matos ${ }^{4}$ (1)}

\author{
1Autora para correspondência. Universidade do Estado da Bahia (Salvador). Bahia, Brasil. daniele.andrade.ba@gmail.com \\ 2-4Universidade do Estado da Bahia (Salvador). Bahia, Brasil. liztorresp17@gmail.com, milheirovitoria1@gmail.com, yasminvm97@gmail.com
}

RESUMO | INTRODUÇÃO: O exercício da escrita e da escuta contribuem para a prática médica de forma ímpar. O recebimento da história do paciente se dá por uma escuta atenta que, para isso, precisa ser treinada. Assim, a escrita é a ferramenta primordial nesse processo. A medicina hoje assume um carácter cada vez mais tecnicista. DISCUSSÃO: A aproximação da Medicina e das ciências humanas, que, para alguns, parece ser inconciliável, ganha espaço na Medicina Narrativa de Rita Charon, através deste exercício cíclico e inesgotável de escrever e escutar. Os livros são capazes de nos fornecer recursos interpretativos e proporcionar um posicionamento mais atento e perspicaz aos comportamentos do paciente de falar ou até mesmo ao se manter em silêncio. Assim que se apreende o que foi escutado, a escrita vem como diálogo consigo mesmo para entender com maior profundidade o que acabamos de experienciar. Entrando nesse complexo enredo do paciente, através da imaginação, abre-se o caminho para desenvolver empatia com o emissor e abre espaço para reflexão do médico em relação ao que ele vivencia. É essencial possuir um arsenal teórico e literário para se conectar com as vivências e o lugar social do paciente. CONCLUSÃO: A medicina não é em si ciência, por isso pressupõe a interpretação, a qual surge também da boa escuta e escrita. Desta forma, essas capacidades promovem uma relação médico(a)-paciente mais horizontal e menos paternalista, dando o protagonismo ao paciente sobre si mesmo e sua dor.

PALAVRAS-CHAVE: Relação médico-paciente. Humanidades. Literatura. Artes. Ensino em saúde. Educação Médica. Comunicação. Medicina Narrativa.
ABSTRACT | INTRODUCTION: The exercise of writing and listening contribute to medical practice in a unique way. The receipt of the patient's history is given by attentive listening that, for this, needs to be trained. Thus, writing is a primary tool in this process. Medicine today takes on an increasingly technical nature. DISCUSSION: The approach of Medicine and the human sciences, which for some, seems to be irreconcilable, gains space in Rita Charon's Narrative Medicine, through this cyclical and inexhaustible exercise of writing and listening more attentively and insightfully to the patient's behaviors of speaking or even to keep silent. As soon as one learns what was heard, writing comes as a dialogue with yourself to understand in greater depth what we have just experienced. Entering this complex storyline of the patient, through imagination, opens the way to develop empathy with the sender and opens space for the doctor to reflect on what he experiences. It is essential to have a theoretical and literary arsenal to connect with the patient's experiences and social place. CONCLUSION: Medicine is not science itself, so it presupposes an interpretation, which also arises from good listening and writing. In this way, these resources promote a more horizontal and less paternalistic doctor-patient relationship giving to the patient the protagonism over himself and his/her pain.

KEYWORDS: Doctor-patient relationship. Humanities. Literature. Arts. Health teaching. Medical Education. Communication. Narrative Medicine 


\section{Introdução}

A prática médica é pautada na relação interpessoal entre o profissional e o paciente, isto é, escuta-se e expressa-se sempre, em uma relação de troca entre pessoas. Sendo assim, o exercício da escuta e da escrita contribuem para a prática médica de forma ímpar. Para além das alterações clínicas e laboratoriais, medo, fragilidade, insegurança, tristeza são comumente sentidos por quem está doente. Há uma pessoa antes e durante a História da Doença Atual e haverá uma depois. É necessário, portanto, saber receber as histórias do paciente, afinal, como explicita Clarice Lispector, "a vida de cada pessoa é passível de um aprofundamento doloroso" ${ }^{\prime \prime}$. Esse recebimento, então, se dá por uma escuta atenta que, para isso, precisa ser treinada. Assim, a escrita é a ferramenta primordial nesse processo.

\section{Desenvolvimento}

Ler/escutar uma narrativa é mergulhar em lugares desconhecidos; é ver através dos olhos do narrador; é ouvir com os ouvidos dos personagens, é estar em lugares onde nunca se esteve. Diante disso, escutar e ouvir distinguem-se: escutar a história de alguém é transportar-se para outro corpo, outro tempo, outras vivências, outros sentidos ${ }^{2}$. Ainda que o médico provavelmente saiba muito mais sobre os pormenores clínicos e biológicos de uma doença, é seu paciente que padece, e não ele. Enquanto na fotografia vemos Frida Kahlo usando seu colete ortopédico (Figura 1), é na pintura $A$ coluna partida (Figura 2) que é possível entender como ela realmente se sente naquele contexto de doença. De forma semelhante, escutar o que o paciente tem a dizer é enxergar a doença pelos olhos de quem sofre.
Durante esse processo, percebemos a leitura como exercício para se saber escutar. Todavia, antes de ler, escrevemos para pôr em ordem o mundo externo e interno a nós ${ }^{3}$. Novamente parafraseando Clarice, às vezes uma linha só basta para salvar um coração'. E isso acontece não por meio de mera grafia, mas, sim, de uma escrita reflexiva ${ }^{4}$, na qual, provavelmente as respostas para suas perguntas serão novas perguntas, e, assim, a escrita apresenta-se como o princípio da própria escuta, como sugere Mia Couto ${ }^{5}$. No ato de escrever, o transporte é muito mais vivo e pessoal, nos esforçamos para nos aproximarmos do paciente de forma mais concreta, visto que, dentro de nós, há interação entre os dois universos de experiências e percepções que fazem aquilo ter sentido ${ }^{6}$. A experiência afetiva da relação com o que se vive, materializa-se em emoções, sentimentos e percepções; é quando apreende-se as experiências com maior nitidez e percebe-se lacunas a serem corrigidas e aprimoradas ${ }^{7}$. Entrando nesse complexo enredo do paciente, através da imaginação, abre-se o caminho para desenvolver empatia e alteridade com o emissor ${ }^{8}$.

A medicina hoje, infelizmente, assume um carácter cada vez mais tecnicista. Existe um abismo cultural entre esses campos na medida em que a medicina se vê como ciência e fala com linguagem científica, buscando uma provável certeza9 . Isso concentra o olhar do profissional na doença e desumaniza não só o(a) paciente, como também a ele mesmo. A procura por uma relação médico-paciente humanística que visa profissionais que tenham a capacidade e a sensibilidade de captar, através da escuta, as mensagens subliminares no discurso da pessoa doente se faz necessária.

A aproximação dessas duas esferas da vida que, para alguns, parecem ser inconciliáveis, ganha espaço na Medicina Narrativa de Rita Charon, através deste exercício cíclico e inesgotável de escrever e escutar ${ }^{?}$. 
Esse novo campo da medicina tem o objetivo de aprimorar a prática clínica trazendo o contar história para o centro dela, pois o médico precisa, além do concerto do corpo, aprender a ver a complexa experiência vivida pela pessoa que enfrenta uma doença ${ }^{7}$. A arte e a literatura, portanto, assumem uma posição fundamental nesse processo, ao explorar os lados mais subjetivos, psicológicos e sociais do ser, os quais representam quem realmente somos e o que queremos. Rita Charon propõe que, quanto mais histórias ouvirmos, lermos e, aqui acrescentamos, escrevermos/criarmos, melhor conseguiremos estabelecer aquela ligação estável, de empatia, com o paciente; isto é, também, escutá-lo e compreendê-lo ${ }^{10}$. A literatura nos torna mais capazes de apreender o subjetivo, entender o que está nas entrelinhas e exercita a capacidade de colocar-se no lugar do outro. Ler $A$ Hora da Estrela, de Clarice Lispector, e Americanah, de Chimamanda N. Adichie, é entender os pormenores da realidade de duas imigrantes: uma nordestina e outra africana, que, apesar de estarem em ambientes completamentes distintos, - a primeira em São Paulo, e a segunda nos Estados Unidos - ambos são hostis e pouco acolhedores ${ }^{11,12}$. Ler Feliz Ano Velho, de Marcelo Rubens Paiva, é enxergar as dores, dificuldades e a superação de uma pessoa com deficiência ${ }^{13}$. O conto Sebastopól no mês de dezembro, de Liev Tolstói, tem uma narrativa imersiva, na qual o leitor se vê como um personagem dentro de uma cidade destruída pela guerra ${ }^{14}$.

Munido da experiência de mergulhar nas mais variadas histórias como essas, o médico olhará para o/a paciente que entra pela porta da clínica, ou está em um leito de hospital, - o qual pode ser um imigrante em um ambiente hostil como Macabéa e Ifemelu; um refugiado que teve sua cidade destruída pela guerra, como Sebastopol; uma pessoa que está lidando com a nova realidade de ter uma deficiência, como Marcelo Rubens Paiva - com outros olhos ${ }^{11-14}$. A literatura cumpre a função de consolidar emoções e pensamentos e enxergar o outro para além do que se vê. É "ante-escutar" tais situações para a pessoa que terá de lidar com elas. Os livros são capazes de nos fornecer recursos interpretativos e proporcionar um posicionamento mais atento e perspicaz aos comportamentos do paciente de falar ou até mesmo ao se manter em silêncio.
Médicos e médicas devem estar sintonizados com as questões de seu tempo ao buscar compreender as principais dimensões da vida humana, como as culturais, econômicas, sociais, de gênero, étnicas e psicológicas que podem interferir no "estar doente". Tais ensinamentos nos levam a compreender uma espécie de "lugar de fala do paciente" - referência ao conceito de lugar de fala recuperado por Djamila Ribeiro que diz sobre as diversidades sociais - no qual o ouvinte deve estar atento às vozes de grupos silenciados ${ }^{15,16}$. Desta maneira, é possível praticar uma escrita mais realista e empática, além de compreender a capacidade individual de reagir a sua nova condição.

Escutar imprescinde empenho para captar os sentidos das palavras usadas pelo paciente. Sendo assim, o paciente não precisa se esforçar para convencer o médico do que sente; ele encontra em nós um receptor, aberto ao diálogo e à viagem intersubjetiva ${ }^{10,17}$. Os pacientes, inclusive, podem atuar de forma ativa na narrativa do médico. Rita Charon mostra aos pacientes o que escreve sobre eles ${ }^{10,17}$. Segundo a autora, seu relato constitui uma hipótese de uma pesquisa subjetiva que somente os pacientes poderiam confirmar. Ela escreve sobre o que o paciente diz, e na visita seguinte, mostra-lhe a descrição, para checar sua própria compreensão sobre o relato do mesmo. O procedimento pode ser repetido em várias visitas com o mesmo paciente, até que cada visita resulte num capítulo sobre sua vida. Logo, o desenvolvimento da história clínica - a partir do entendimento do paciente como sujeito - será direcionada para aspectos que outrora seriam negligenciados pela vivência médica guiada pelo conhecimento puramente científico.

Engana-se, ainda, quem acha que, com o advento da inteligência artificial e de Sistemas de Apoio à Decisão Clínica, por exemplo, a preocupação com a formação médica deve ser menor. Esse lado subjetivo, humano e de conexão é o que a máquina é incapaz de fazer 18 . O vínculo, a adaptação da linguagem, a explicação melhor aplicada ao contexto de vida daquela pessoa, o alívio de angústias e tensões só podem ser feitos por outra pessoa. Dessa forma, o exercício da escrita e da escuta encaixam-se perfeitamente como ferramentas para também responder a essa nova realidade. (Figuras 4 e 5) 
Assim que se apreende o que foi escutado, a escrita vem como o diálogo consigo mesmo para entender com maior profundidade o que acabamos de experienciar, compreender não apenas o resultado da interação com o outro, como também em qual plano ela se deu ${ }^{3}$. Dessa maneira, o exercício da escrita é um instrumento ímpar para se compreender a vida e, para além da doença, a experiência da doença pelo paciente, no que tange a distinção entre o que é nosso e o que é dele na história2,6. Após a interação primeira de se sentir no lugar do outro, colocando em evidência os seus sentimentos e os dele, precisamos nos questionar quais sofrimentos, sentimentos e angústias são nossos.

Esse tensionamento é o que caracteriza o caráter dialógico do exercício da escrita para o médico, culminando em um processo de autoconhecimento, o qual apenas o exercício contínuo consigo mesmo é capaz de nos orientar ${ }^{19}$. Então, escrever toma dois papéis, o de materialização das experiências de se fazer sentido; e o terapêutico, de autoconhecimento - na medida em que o escrever promove uma interação intersubjetiva mais intensa, ou seja, entre os mundos do paciente e do profissional $2, \frac{8}{}$. Uma mente tranquila talvez seja capaz de realizar esse trabalho sem maiores aflições, mas, em um cotidiano de "entra-e-sai", experienciando diversas histórias e decisões, o papel e o lápis são grandes aliados na prática médica. A narrativa escrita proporciona o acesso a um conhecimento não apenas sobre os pacientes e suas patologias, mas também sobre o próprio médico ${ }^{2,6}$. A reflexão sobre o que ele vivencia proporciona ao profissional uma maior confiança, uma capacidade de reconhecer e prevenir erros e o desenvolvimento do compromisso ético com os pacientes, caminhando para o desenvolvimento da empatia e alteridade ${ }^{2,20}$.

\section{Conclusão}

Escutar é ler com os ouvidos e escrever é ler através de nós mesmos. Se é apenas com o exercício que se aprende, então é exercitando a escrita, a leitura e a escuta, que a prática médica pode ser aprimorada. Cada pessoa é diferente, então, as formas de se expressar também o serão e, portanto é preciso que a(o) profissional tenha, para além do arsenal medicamentoso, um vasto arsenal teórico e literário para que possa se conectar com as vivências e lugar social de quem está doente. A medicina não é em si ciência e, assim como a literatura, necessita da capacidade humana de elucubrar e interpretar.

Com a obtenção deste recorte no tempo da vida deste indivíduo, o narrador médico e a narradora médica têm a função de se confrontarem e refletir com base na sua visão de mundo e crenças. Na Medicina Narrativa, no papel de ouvinte e, ao mesmo tempo, de narrador e leitor da história que está sendo contada, o(a) médico(a) tem a missão de acompanhar o desenrolar dos fatos e captar os sinais entrelaçados no relato do protagonista e contar outras tantas histórias a partir disso com a escrita cujo passo inicial foi escutar.

Ante o exposto, ressaltamos a importância da inserção das chamadas Humanidades Médicas, as quais têm como um dos aspectos a inter-relação entre medicina e literatura aos currículos de formação médica. Sendo assim, o cuidado integral e a relação horizontal médico(a)-paciente ganharão espaço ao superar a visão paternalista e dar o protagonismo necessário ao paciente sobre si mesmo e a sua dor. 
Figura 1. Frida Kahlo pintando seu colete ortopédico

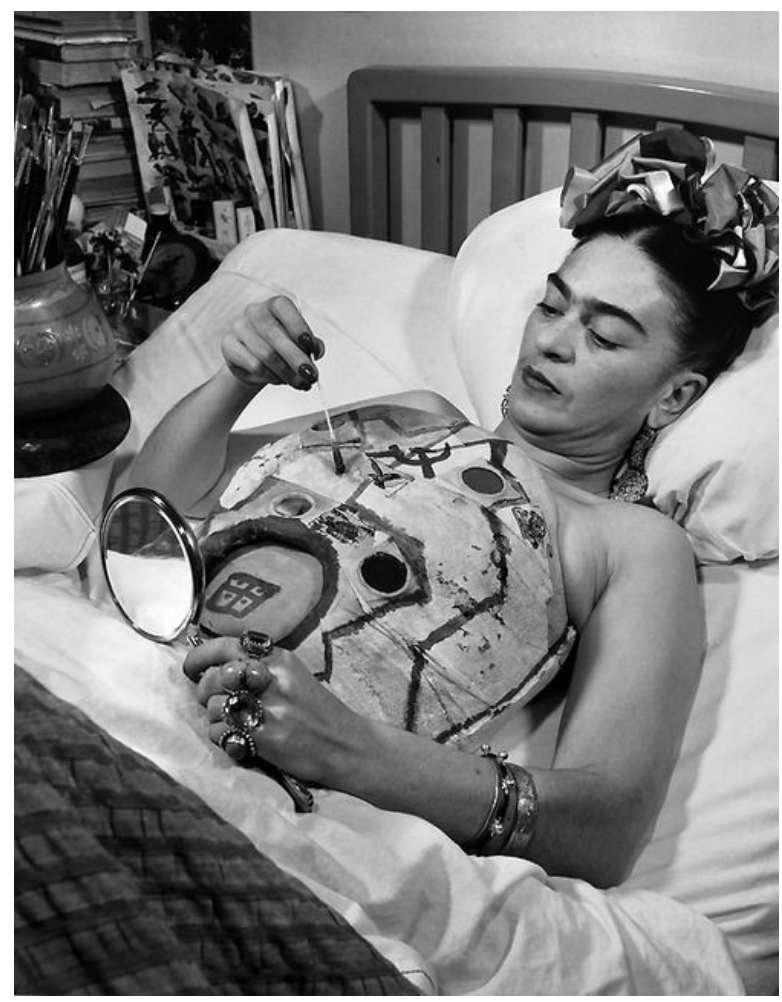

Fonte: Coleção e Arquivo da Fundación Televisaa.

Figura 2. "A Coluna Partida", Frida Khalo (1944)

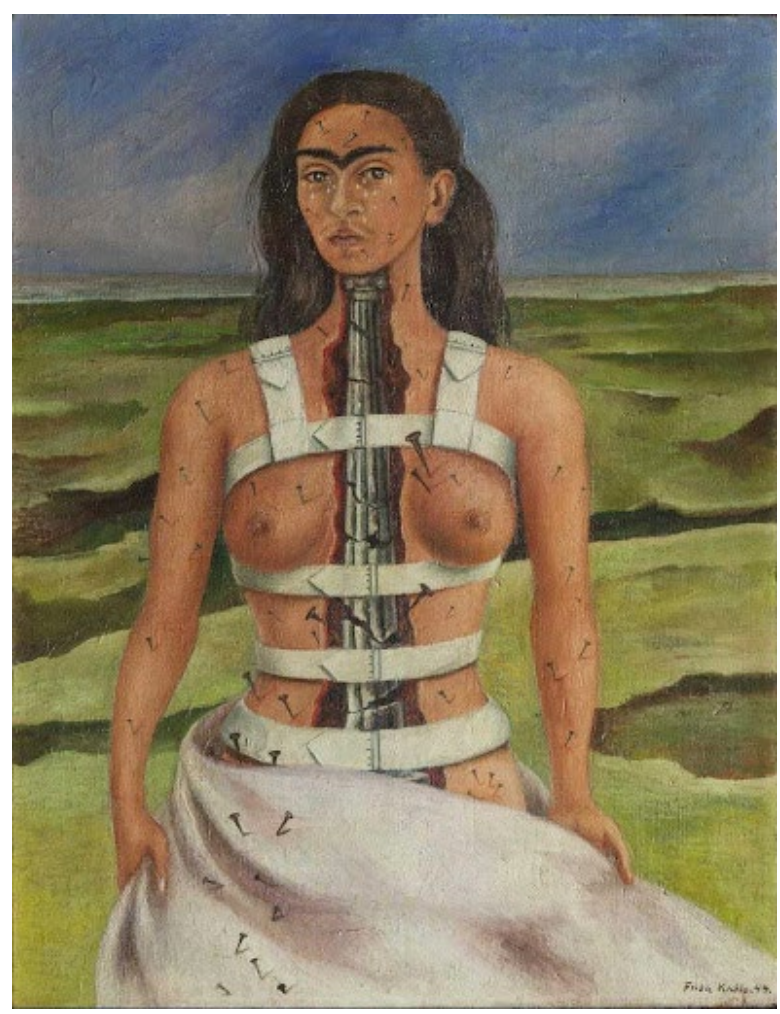

Fonte: Google Arts \& Culture ${ }^{\mathrm{b}}$.

${ }^{a}$ Citado em 2020 ago. 21. Disponível em: https://vintagenewsdaily.com/intimate-photographs-of-frida-kahlo-painting-on-her-bed-during-the-1950s/

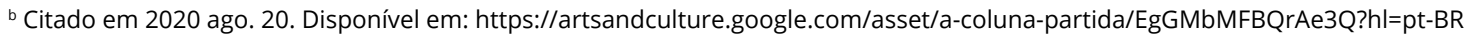




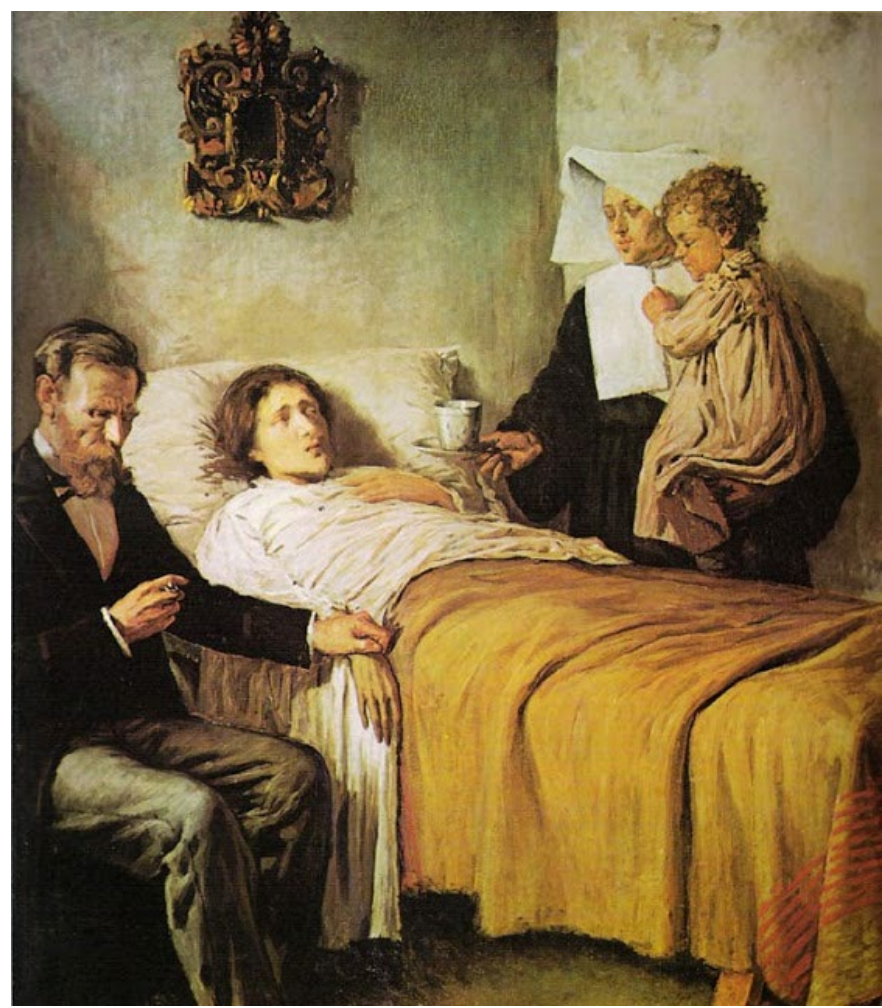

Fonte: Museu Picasso, Barcelonac.

Figura 5. Updates of famous medical paintings, this time Pablo Picasso's "Science and Charity" (1897)

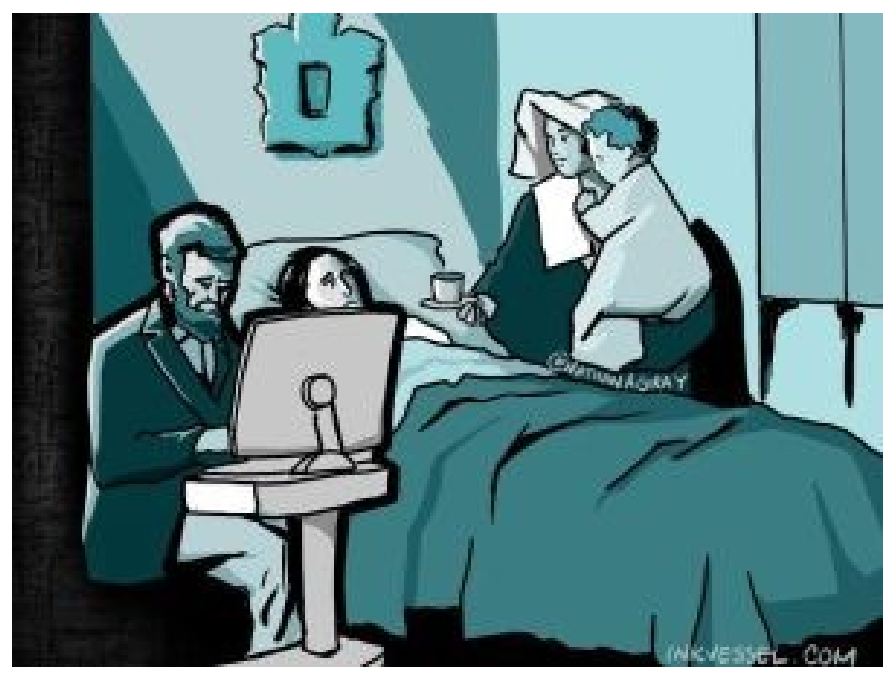

Fonte: Página de Nathan Gray do Twitter ${ }^{d}$.

\section{Agradecimentos}

Agradecemos às professoras lêda Maria Barbosa Aleluia, Maristela Rodrigues Sestelo, Nelma Aronia Santos que criaram esse projeto bonito e muito importante à nossas vidas e a nossa formação. As reflexões sobre o que faz de nós médicas e, mais do que isso, sobre o nosso lugar no mundo, de forma integral, como tanto abordamos ao longo deste ensaio são imprescindíveis e devemos fazê-las cotidianamente. Somos, antes de tudo, pessoas, e as artes, as ciências humanas, o estudo da linguagem e os recursos literários nos acompanham naturalmente. 
Também agradecemos aos nossos colegas, entre os quais compartilhamos pensamentos, inquietações, sanamos dúvidas com quem pudemos, mesmo que virtualmente, dividimos a emoção de nos encontrarmos em uma outra possibilidade de Medicina, sensível e integradora dos seres humanos, engajada nas causas sociais, de tanta desigualdade e diversidade, empática e, de fato, feita em meio ao amor. Ninguém solta a mão de ninguém. Gostaríamos de fazer um agradecimento especial a Jardelina Oliveira Passos Moura, com quem dialogamos sobre a arte e a função da escrita para a escuta, bem como para aqueles que a exercitam, consolidando a tese a ser discutida nesse ensaio.

\section{Contribuições das autoras}

Andrade DS, Pedreira LT, Milheiro VSCM e Matos YV foram responsáveis pela concepção do texto, da escrita e da revisão final.

\section{Conflitos de interesses}

Nenhum conflito financeiro, legal ou político envolvendo terceiros (governo, empresas e fundações privadas, etc.) foi declarado para nenhum aspecto do trabalho submetido (incluindo, mas não se limitando, a subvenções e financiamentos, participação em conselho consultivo, desenho de estudo, preparação de manuscrito, análise estatística, etc.).

\section{Referências}

1. Lispector C. Um sopro de vida. Rio de Janeiro: Rocco; 1999.

2. Barison OL. A escuta da escrita da escuta: emoções através do relato clínico. J. psicanal [Internet]. 2017. [citado em 2020 ago. 21]; 50(93). Disponível em: http://pepsic.bvsalud.org/scielo. php?script=sci_arttext\&pid=S0103-58352017000200017

3. Folha do Mate. O exercício da escrita [Internet]. 2020. [citado em 2020 ago. 21]. Disponível em: https://folhadomate.com/ variedades/na-pilha/o-exercicio-da-escrita/

4. Rodrigues JD. Slow medical education: a leitura e a escrita como forma de despertar para a prática médica mais reflexiva [Internet]. Slow Medicine; 2018. [atualizado em 2018 mai. 28; citado em 21 de agosto de 2020]. Disponível em: https://www. slowmedicine.com.br/slow-medical-education-a-leitura-e-aescrita-como-forma-de-despertar-para-a-pratica-medica-maisreflexiva/

5. Tambellini F. O princípio da escrita é escutar [Internet]. Estadão; 2019. [atualizado em 2019 set. 17; citado em 21 de agosto de 2020]. Disponível em: https://educacao.estadao.com.br/blogs/ escola-projeto-vida/o-principio-da-escrita-e-escutar/

6. Sardenberg MLC. Medicina Narrativa [Internet]. Rede Humaniza SUS; 2012. [atualizado em 2012 abr. 24; citado em 2020 ago. 21]. Disponível em: http://redehumanizasus.net/12793-medicinanarrativa/
7. Charon R. 2018 Jefferson Lecture in the Humanities with Dr. Rita Charon [Internet], Washington, D.C; 2018 [citado em 2020 ago. 21]. Vídeo: 1h06. Disponível em: https://www.youtube.com/ watch?v=7yIOrdQEAj8\&feature=youtu.be

8. Benedetto MAC. Entre dois continentes: literatura e narrativas humanizando médicos e pacientes. O Mundo da Saúde [Internet]. 2010 [citado em 2020 ago. 21]; 34(3):311-9. Disponível em: http:// www.saocamilo-sp.br/pdf/mundo_saude/77/311a319.pdf

9. Scliar M. Literatura e medicina: o território partilhado . Cad. Saúde Pública [Internet]. 2000 [citado em 2020 ago. 21]; 16(1):2458. Disponível em: https://www.scielosp.org/article/csp/2000. v16n1/245-248/

10. Couto CRO. Ora direis, ouvir histórias! Sobre os fundamentos de medicina narrativa [Internet]. Slow Medicine; 2019 [2019 fev. 2019; citado em 21 de agosto de 2020]. Disponível em: https:// www.slowmedicine.com.br/ora-direis-ouvir-historias-sobre-osfundamentos-de-medicina-narrativa/

11. Lispector C. A hora da estrela. Rio de Janeiro: Rocco; 1998.

12. Adichie CN. Americanah. São Paulo: Companhia das Letras; 2014.

13. Paiva MR. Feliz ano velho. São Paulo: Círculo do Livro; 1982.

14. Tolstói L. Contos Completos. São Paulo: Cosac Naify; 2015. p. 159-80.

15. Ribeiro D. Dijamila Ribeiro: "o que é lugar de fala?" [Internet]. Oficinas culturais do estado de São Paulo; 2018. Vídeo: 1 h31. Disponível em:https://www.youtube.com/watch?v=evE4GjXVYIQ

16. Freitas TT. RIBEIRO, Djamila. O que é lugar de fala?. Belo Horizonte: Letramento, 2017. 112 p. (Feminismos Plurais). Horiz. antropol. 2019;25(54). https://doi.org/10.1590/s0104$\underline{71832019000200015}$

17. Grossman, E, Cardoso MHCA. As narrativas em medicina: contribuições à prática clínica e ao ensino médico. Rev. bras. educ. med. 2006;30(1): 6-14. https://doi.org/10.1590/S010055022006000100002

18. Lobo LC. Inteligência Artificial e Medicina. Rev. bras. educ. med. 2017; 41(2):185-93. https://doi.org/10.1590/198152712015v41n2esp

19. Bakhtin M. Estética da criação verbal. 3a. ed. São Paulo: Martins Fontes; 2000. p. 327-359.

20. Cassorla RMS. O estudante de medicina e o paciente: uma aproximação à prática médica. Rev. psiquiatr. 2006;28(2):219-21. https://doi.org/10.1590/S0101-81082006000200017 